\title{
Smoke control in case of fire in a large car park: Full-Scale Experiments
}

\author{
X. Deckers ${ }^{1,2}$, S. Haga ${ }^{1,3}$, B. Sette ${ }^{4}$ and B. Merci ${ }^{1}$ \\ ${ }^{1}$ Ghent University, Dept. Flow, Heat and Combustion Mechanics, Belgium \\ ${ }^{2}$ Fire Engineered Solutions BVBA, Belgium \\ ${ }^{3}$ NorConsult, Norway \\ ${ }^{4}$ WFRGent NV, Belgium
}

\begin{abstract}
Temperature measurements are presented as obtained in a full-scale experimental campaign on large closed car park fires. Since the main objective of the study is the investigation of the impact of a smoke and heat control (SHC) system with forced mechanical horizontal ventilation on the smoke pattern in case of a car park fire, the desired fire heat release rate (HRR) is imposed by means of well-controlled liquid pool fires. Different parameters are varied: the fire HRR; the smoke extraction flow rate; the flow patterns (through modification of inlet air opening); and the presence (or not) of a transversal beam. Not surprisingly, less smoke back-layering is observed for lower fire HRR and higher smoke extraction rate, the effect of the latter being more important. The exact position of the extraction fans is not essential, when they are not close to the fire source. The impact of the flow pattern is substantial: when smoke is trapped inside a recirculation region, the smoke and heat are not removed effectively. A transversal beam can block the smoke, even for high HRR. The primary effect of jet fans (induction type, 50N) in the study at hand is a local cooling effect, not a significant impact on the global flow pattern. For the cooling effect to be observed, the jet fans must not be in a smoke filled region.
\end{abstract}

Keywords: Car park fire safety; smoke and heat control; full-scale experiments 


\section{Introduction}

Fire safety is an important issue in underground car parks. Recently, two large research projects have been executed in Europe $[1,2]$. The outcome of the full-scale experimental campaigns can be considered an important update of test results from the 90s [3]. A key result of [1,3] concerns the fire heat release rate (HRR) to be used in design calculations for fire safety systems in car parks. In [4], a discussion is devoted to the design fire HRR for large closed car park fires. In [4], also conceptual aspects, including fundamental differences from tunnel fires, are discussed regarding smoke and heat control (SHC) by forced horizontal ventilation in case of a car park fire. Therefore, this is not repeated here.

Rather, the main purpose of the paper at hand is to summarise the findings from temperature measurements, obtained in a full-scale experimental campaign, set up to examine the impact of a SHC system with forced horizontal ventilation on the smoke pattern in case of a car park fire, for a wide range of conditions. To that purpose, a large number of full-scale fire experiments have been performed, varying the following parameters:

\section{- Fire HRR;}

- Smoke extraction flow rate;

- Opening for incoming air (so that different flow patterns have been created);

- Presence (or not) of a transversal beam.

The impact of jet fans (induction type, $50 \mathrm{~N}$ each) is also addressed in a number of experiments.

The main objectives of the paper are the visualization of the effect of the parameters mentioned and the interpretation of the observations made. For a summary of the complete set of experimental conditions examined, the reader is referred to [2]. 
It is important to appreciate that in all experiments as discussed below, the fire HRR is considered an input value. Indeed, well-controlled liquid pool fires have been used, rather than real-car fires. As mentioned, the focus of the study at hand is not on the design fire HRR, but on the effect of the SHC system on the smoke pattern in given fire and ventilation conditions. This research is motivated by the need for scientific support in the development of standards and guidelines for design of SHC systems, e.g. [5-7].

In the discussion of the experimental results, reference is sometimes made to [8], where numerical CFD (Computational Fluid Dynamics) simulations, obtained with FDS, version 5.4.1 [9], are presented for the experiments at hand. Obviously, the results of [8] are not repeated in the present paper. They are only briefly mentioned where helpful for clarification of the experimental observations made.

\section{Experimental Set-up}

A lightweight steel construction has been built on the premises of WFRGENT NV (Ghent, Belgium) to serve as test rig, resembling the geometrical configuration of a simple rectangular closed car park. The horizontal dimensions are $30 \mathrm{~m}$ (depth) x $28.6 \mathrm{~m}$ (width), corresponding to a floor area of $858 \mathrm{~m}^{2}$. The ceiling height varies from $2.8 \mathrm{~m}$ to $2.6 \mathrm{~m}$ as the roof has a slight sideward inclination in order to easily remove rain water from the roof.

As mentioned in the introduction, the purpose of the paper at hand is to examine, for a wide range of conditions, the impact of a SHC system with forced mechanical horizontal ventilation on the smoke pattern, given a car park fire. Therefore, in the experiments, the fire source is a well-controlled liquid pool fire, since in a real-car fire the HRR is less controllable [2]. 
Obviously, a liquid pool fire, with controlled fire source HRR and area, is not identical to a realcar fire. However, for the sake of the present paper, namely the investigation of smoke patterns as a result of the combined effects of a fire source and an activated SHC system, the details of the fire source are not essential. Indeed, as long as the HRR is identical (and the fire source area not too strongly different), the resulting smoke pattern is very similar, certainly when the direct surroundings of the fire source are not considered. In a number of standards (e.g. [5-7]), where the basic philosophy behind the standard is the assistance of a fire service intervention, the main objective is to create a smoke-free region from the point of entrance (for the fire service) into the car park up until a distance of 10 to $15 \mathrm{~m}$ away from the fire source. It is envisaged that the fire service can effectively extinguish the fire if they can approach the fire source up to that distance. So far away from the fire source, the details of the fire are not important for the fire-induced smoke dynamics. This argument justifies the use of the liquid pool fire for the purpose of the present paper.

The liquid pool fire consists of hexane $\left(\mathrm{C}_{6} \mathrm{H}_{14}\right)$ in a tray of dimensions $3 \mathrm{~m}$ x $1.5 \mathrm{~m}$ x $0.5 \mathrm{~m}$. The hexane (density: $655 \mathrm{~kg} / \mathrm{m}^{3}$ ) floats on water: the tray is first filled with water up to a height of $0.45 \mathrm{~m}$. The water serves to cool the tray.

The fire source is positioned in the centre of the car park (from $\mathrm{Y}=13.5 \mathrm{~m}$ to $\mathrm{Y}=16.5 \mathrm{~m}$ and from $X=13.55 \mathrm{~m}$ to $X=15.05 \mathrm{~m}$, Figure 1 ). The liquid hexane is fed into the burner by means of a volumetric pump. Through the mass flow rate, the fire HRR is controlled, knowing that the heat of combustion of hexane is $44.7 \mathrm{MJ} / \mathrm{kg}$. Pressurized air is issued at high velocity from a series of small holes (with diameter equal to $1 \mathrm{~mm}$ ). Although the mass flow rate is low (in the order of $0.05 \mathrm{~kg} / \mathrm{s}$ ), this pressurized air mixes with the hexane vapour directly above the fuel 
surface and serves as primary air for combustion, effectively stabilizing the flames close to the burner surface.

The ceiling, beams and columns have been protected by $5 \mathrm{~cm}$ thick silicate fiber insulation, able to withstand temperatures up to $1200{ }^{\circ} \mathrm{C}$, within a square area of $6 \mathrm{~m}$ by $6 \mathrm{~m}$ around the fire source. Further away, $5 \mathrm{~cm}$ thick mineral wool insulation, suited for temperatures up to $650{ }^{\circ} \mathrm{C}$, has been installed. Chicken wire has been added as additional precaution to prevent objects from falling.

Four extraction fans of $50000 \mathrm{~m}^{3} / \mathrm{h}$ nominal extraction rate each, have been installed at the back side of the car park. The fans, which have a diameter of $1 \mathrm{~m}$ and a vertical shaft, are positioned in the ceiling, with their centre at a distance of $1.1 \mathrm{~m}$ from the rear wall, equally spread over the width of the car park (centre at $X=6.7 \mathrm{~m}, 10.5 \mathrm{~m}, 18.1 \mathrm{~m}$ and $21.9 \mathrm{~m}$, Figure 1). The middle two fans are frequency controlled (0-50 Hertz) to adjust the extraction flow rate, while the outer two are on/off. The motivation hereto was to examine whether the exact position of the extraction fan strongly affects the smoke pattern (knowing that the extraction fan is more than $10 \mathrm{~m}$ away from the fire source). The extraction rates were the highest possible within the project budget. Note that a total extraction rate of $4 \times 50000 \mathrm{~m}^{3} / \mathrm{h}$ corresponds to an air velocity of $0.72 \mathrm{~m} / \mathrm{s}$ (assuming the velocity uniform in a cross-section of $28.6 \mathrm{~m} \times 2.7 \mathrm{~m}$ ).

In a few experiments, two 'jet fans' of the 'induction' type of $50 \mathrm{~N}$ each, have also been activated. It is clearly indicated below when this is the case. Unless mentioned otherwise, the jet fans are not present in the experiments. Their exit area is $0.6 \mathrm{~m}$ (width) $\mathrm{x} 0.15 \mathrm{~m}$ (height), with a downward angle of about $25^{\circ}$, and the flow rate is nominally $7000 \mathrm{~m}^{3} / \mathrm{h}$ per jet fan. The exit area of the fan was placed at $\mathrm{Y}=2 \mathrm{~m}$, i.e. $2 \mathrm{~m}$ inwards from the open side, in the middle of 2 column 
rows (jet fan centerline at $\mathrm{x}=8.5 \mathrm{~m}$ and $\mathrm{x}=20.1 \mathrm{~m}$ ), as shown in Figure 1. More details are found in [2]. In general, though, for the experiments at hand, the impact of the jet fans on the smoke pattern is very small, as discussed below. Therefore a detailed description of the jet fans is not given here, in order not to create the impression they are an essential part of the experimental campaign.

The front side opening of the car park has been made modular, in order to examine the impact of the position and size of the openings for incoming air on the performance of the SHC system. Indeed, different flow patterns are established this way, as discussed below.

The front and back walls, the roof and the upper $30 \%$ of the side walls consist of steel deck $(\mathrm{k}=$ $\left.45 \mathrm{~W} /(\mathrm{m} . \mathrm{K}) ; \mathrm{c}=460 \mathrm{~J}(\mathrm{~kg} . \mathrm{K}) ; \rho=7850 \mathrm{~kg} / \mathrm{m}^{3}\right)$. The floor and the bottom part of the side walls are in concrete $\left(\mathrm{k}=0.2 \mathrm{~W} /(\mathrm{m} . \mathrm{K}) ; \mathrm{c}=900 \mathrm{~J}(\mathrm{~kg} \cdot \mathrm{K}) ; \rho=2200 \mathrm{~kg} / \mathrm{m}^{3}\right)$. The construction is supported by painted mild steel columns and longitudinal beams of $24 \mathrm{~cm}$ thickness.

In order to monitor the wind velocity, wind direction and air temperature during the experiments, a weather station has been installed on the roof.

Approximately 120 bare-bead K-type thermocouples have been put in place (Figure 1), a few centimeters below the insulated car park ceiling. The temperature measurements serve as indication for the presence of smoke. This is justified since the thermal diffusivity is of the same order of magnitude as the (species) diffusivity of smoke. Therefore, a temperature rise can be used as indication for the presence of smoke. E.g. in [10] this concept has also been applied to quantify smoke back-layering, the primary observation of interest in the present paper. Direct scaling of temperature measurements to smoke concentration/visibility is not possible: the concentration (and composition) of smoke depends on many factors, including the fuel type and 
ventilation conditions. Also, radiation depends on the concentration (and composition) of smoke. As such, a temperature rise indicates the presence of smoke, but by no means provides information on the concentration or composition of smoke. This is not an issue for the paper at hand. Consequently, the absolute temperature values (for which a radiation correction to the measurement data would be necessary) are less important than the determination of the region where a temperature rise is observed, as this resembles the smoke pattern under the car park ceiling.

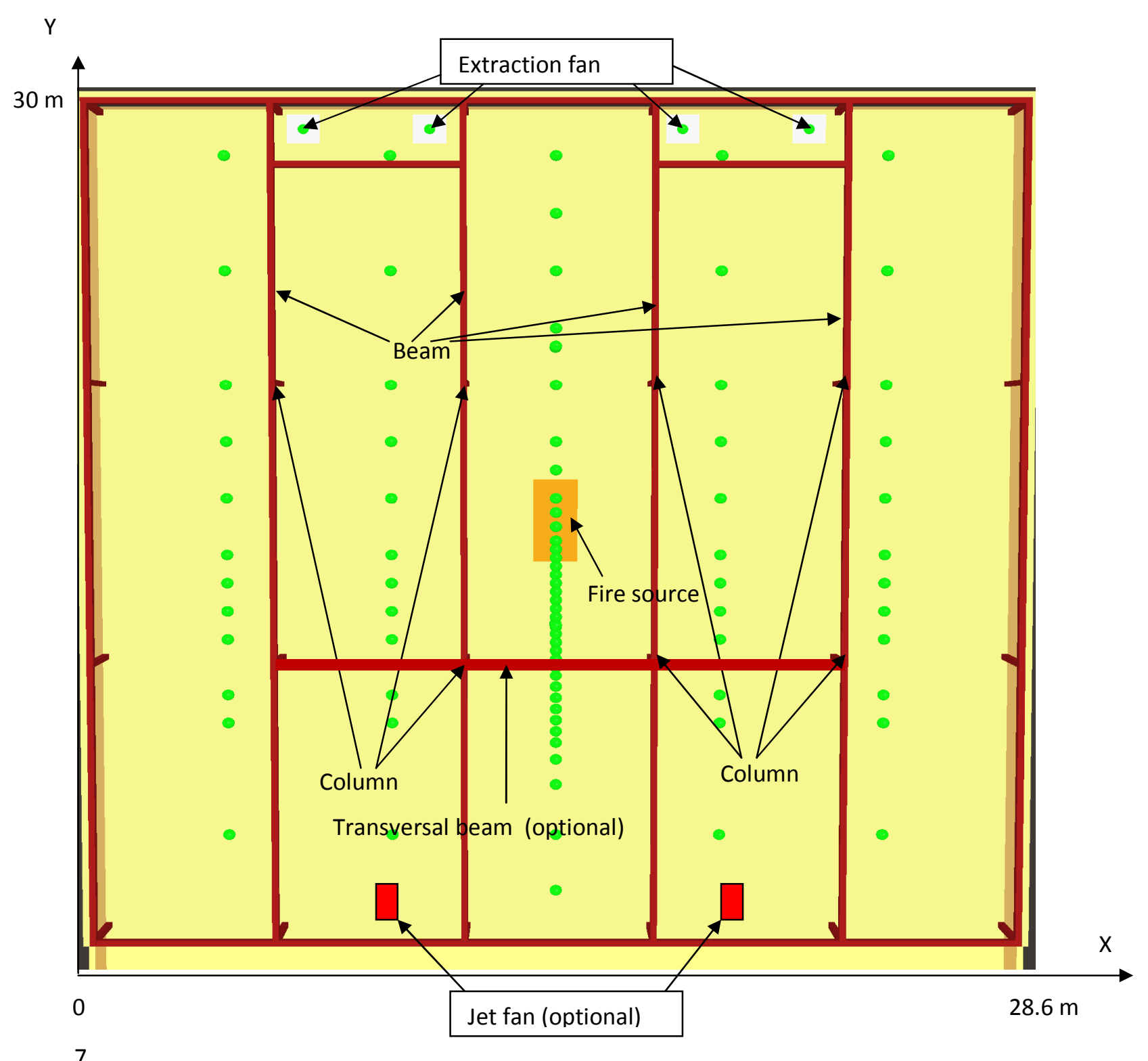



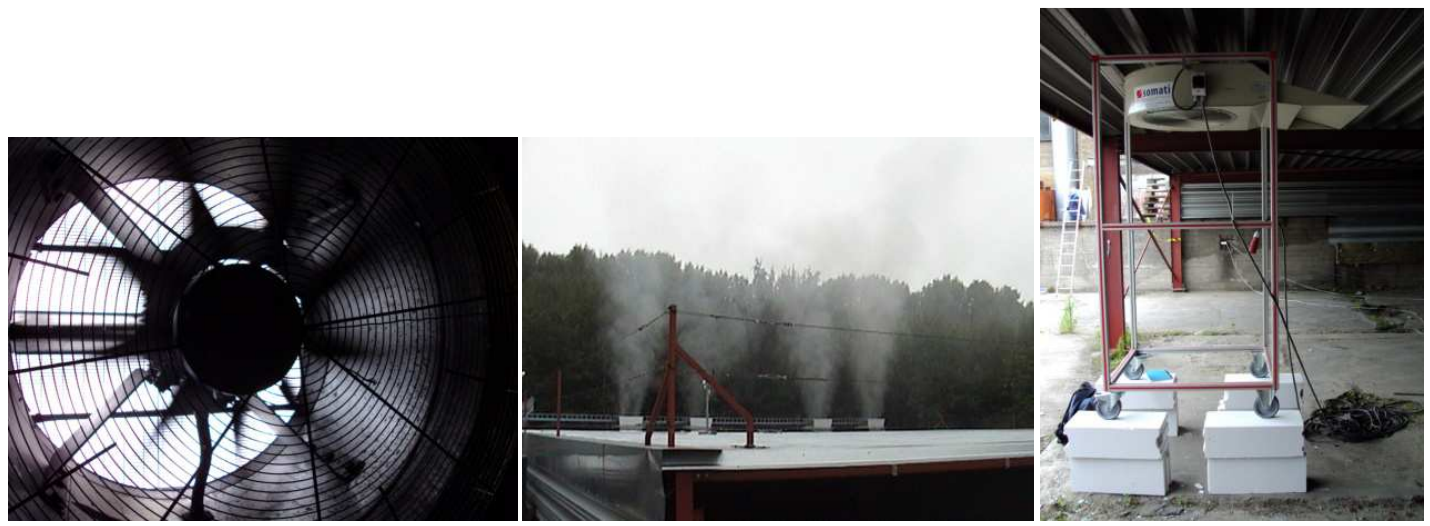

Figure 1. Top: Schematic overview of the full-scale $(28.6 \mathrm{~m}$ wide x $30 \mathrm{~m}$ long x $2.6-2.8 \mathrm{~m}$ high) experimental car park configuration with indication of coordinate axes. Green dots refer to thermocouple positions ( 5 rows: $X=4.3 \mathrm{~m}, 9.3 \mathrm{~m}, 14.3 \mathrm{~m}, 19.3 \mathrm{~m}$ and $24.3 \mathrm{~m}$ ). The fire source is positioned in the middle of the car park (from $\mathrm{Y}=13.5 \mathrm{~m}$ to $\mathrm{Y}=16.5 \mathrm{~m}$ and from $\mathrm{X}=13.55$ $\mathrm{m}$ to $\mathrm{X}=15.05 \mathrm{~m})$. The longitudinal support beams are positioned at $\mathrm{X}=5.7 \mathrm{~m}, 11.4 \mathrm{~m}, 17.2 \mathrm{~m}$ and $22.9 \mathrm{~m}$. The transversal beam (optional) is positioned at $\mathrm{Y}=10 \mathrm{~m}$, from $\mathrm{X}=5.8 \mathrm{~m}$ to $22.8 \mathrm{~m}$. The extraction fans have their centre at $1.1 \mathrm{~m}$ from the back wall $(\mathrm{Y}=28.9 \mathrm{~m})$ and at positions $\mathrm{X}$ $=6.7 \mathrm{~m}, 10.5 \mathrm{~m}, 18.1 \mathrm{~m}$ and $21.9 \mathrm{~m}$.

Bottom: picture of a single extraction fan from the inside of the car park (left), the 4 extraction fans from the outside of the car park (middle) and a jet fan (right). 


\section{Measurement Results: Presentation and Accuracy}

As mentioned in the previous section, the measurement data basically consist of temperature fields as measured by the bare-bead K-type thermocouples under the ceiling. The data acquisition rate has been set to $0.1 \mathrm{~Hz}$. The results below are presented as averages during the steady state conditions. Averages are typically taken over periods of at least 5 minutes.

There are some experimental uncertainties in the temperature measurements.

Firstly, the accuracy of the fuel supply rate is $0.11 / \mathrm{min}$. This corresponds to an absolute error in HRR of $75 \mathrm{~kW}$. Whereas this error is small for the $4 \mathrm{MW}$ fires, it is not for the lower HRR values (e.g. $250 \mathrm{~kW})$.

Secondly, the nominal extraction flow rate of $50000 \mathrm{~m}^{3} / \mathrm{h}$ for each extraction fan at full power, has been confirmed by means of line measurements of velocity in the fans' exit plane. Velocity fluctuations up to $+/-15 \%$ of the mean value have been measured.

Another possible source of uncertainty in the experiments, in the light of comparison to numerical simulations, concerns leakage of air through the construction. Indeed, it was not possible to make the car park construction completely airtight. The leakage gaps have been stuffed with insulation material wherever possible, so that their possible effect on the measurements is reduced to within the global uncertainty margin, caused by the fuel supply and the imposed smoke extraction rate [2].

Similarly, the possible reduction in effective fire HRR due to the cooling effect of the water, which is continuously fed into the burner at $15{ }^{\circ} \mathrm{C}$ and which leaves the burner at higher temperature, is small. The heat losses by the heating up of the cooling water have not been 
measured, but from earlier experience (e.g. [11]) it is known that this heat flow is not substantial and within the other experimental uncertainty margins (particularly of the fire HRR).

Finally, the uncertainty due to wind is worth mentioning. Fortunately, during the experiments, the wind conditions have been very mild (average wind speed around $0.25 \mathrm{~m} / \mathrm{s}$, with occasional gusts of less than $2 \mathrm{~m} / \mathrm{s}$ ). The extraction fans blowing in the vertical direction, they need not overcome possible wind induced over-pressure. Yet, temperature fluctuations near the inlet opening of the car park are clearly higher than a few meters inward (see below), which indicates wind effects on temperature measurements near the inlet (and near the inlet only).

Finally, the velocity field measured indicate a downward flow angle of $25^{\circ}$ within the first meters behind the jet fans (when operational), along with non-uniformity of the horizontal velocity components, most probably because the fan is not positioned centrally inside the jet fan device. In general, detailed information on the flow pattern at the jet fan exit plane and the first few meters downstream can be important to guarantee reliable CFD simulations with jet fans. With the information currently available on the technical specification sheets of jet fans (velocity, flow rate and thrust), the characteristics of the jet flow are not sufficiently described. [8]. However, as mentioned in the previous section, activation of the jet fans hardly affects the experimental observations in the study at hand (see below), so no detailed flow measurements have been pursued and more discussion of the jet fans is also considered unnecessary here. 


\section{Discussion of measurement data}

In [2], all measurements are discussed. Only a subset of results is presented here, in terms of time-averaged temperatures for a number of configurations. The bars around the data indicate the minimum and maximum values measured during the time interval as used for averaging the data (see previous section).

In section 4.c, an elaborate discussion is devoted to the impact of the inlet opening for incoming air on the smoke pattern. However, the notation for the inlet opening configurations is already introduced first in Table 1. The letter ' $O$ ' refers to 'open', while ' $\mathrm{X}$ ' denotes 'blocked'. Only the OOOOO configuration gives rise to a relatively uniform oncoming air flow. In all other configurations, recirculation regions occur behind the $\mathrm{X}$ zones [8].

\begin{tabular}{|l|l|}
\hline Notation & Description \\
\hline XXXXO & Inlet opening 80\% blocked; only the rightmost part is open. \\
\hline OXXXO & Inlet opening 60\% blocked; the closure is in the middle. \\
\hline XXOXX & Inlet opening $80 \%$ blocked; the opening is in the middle. \\
\hline OOOOO & Inlet opening is fully open. \\
\hline
\end{tabular}

Table 1. Short notation for inlet opening configuration.

\section{a. Impact of Fire Heat Release Rate}

Figure 2 presents mean temperature values along the centerline $(X=14.3 \mathrm{~m}$, Figure 1$)$ under the ceiling for the OOOOO configuration. The smoke extraction rate is set to $200000 \mathrm{~m}^{3} / \mathrm{h}$. Results are compared for 4 HRR values: $200 \mathrm{~kW}, 500 \mathrm{~kW}, 1.25 \mathrm{MW}$ and $4 \mathrm{MW}$.

Obviously, the temperatures increase with increasing HRR (note the different vertical axis scale in the top and bottom figure). Also, the maximum temperatures are found around $\mathrm{Y}=16.5 \mathrm{~m}$, which is above the back side of the burner (Figure 1). This is due to back-ward tilting of the flames (see below, Figure 3). 
In general, the shapes of all profiles are quite similar. There is a gradual temperature decrease from the burner towards the inlet of the car park (i.e. from $\mathrm{Y}=13.5 \mathrm{~m}$ towards $\mathrm{Y}=0 \mathrm{~m}$ ): the smoke, driven upward by the strong buoyant force above the fire source, meets the low car park ceiling very rapidly, with a strong ceiling jet phenomenon. The smoke is then pushed horizontally forward underneath the low ceiling towards the car park inlet. It cools down by mixing with the incoming fresh air. Around the burner, say until $\mathrm{Y}=18 \mathrm{~m}$, there is a hightemperature region, including backward flame tilting, as mentioned. This becomes more clearly visible for higher HRR values. As the hot gases approach the extraction fans ( $\mathrm{Y}>18 \mathrm{~m})$ they cool down, primarily by mixing with the air flow, caused by the extraction rate.

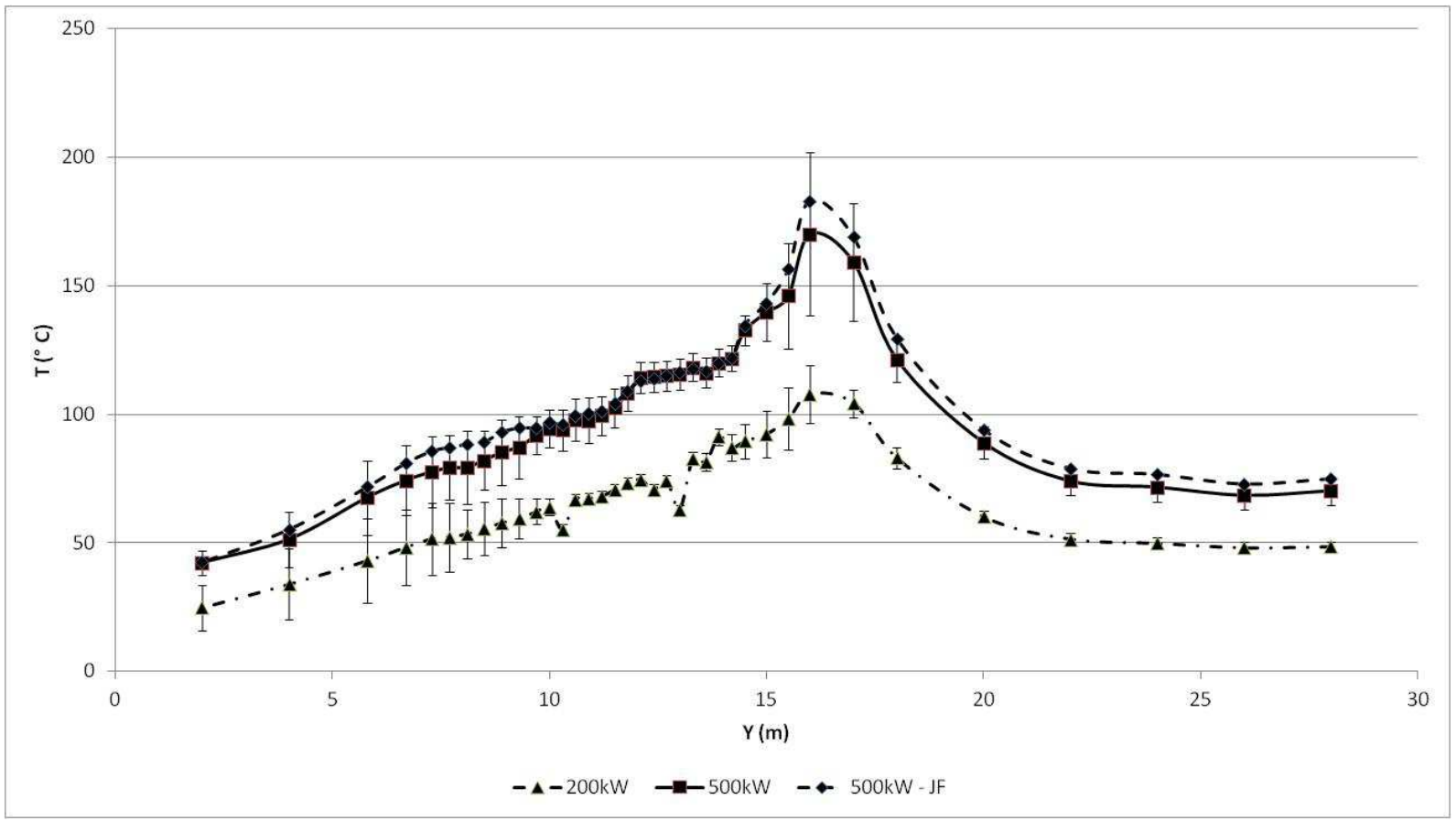




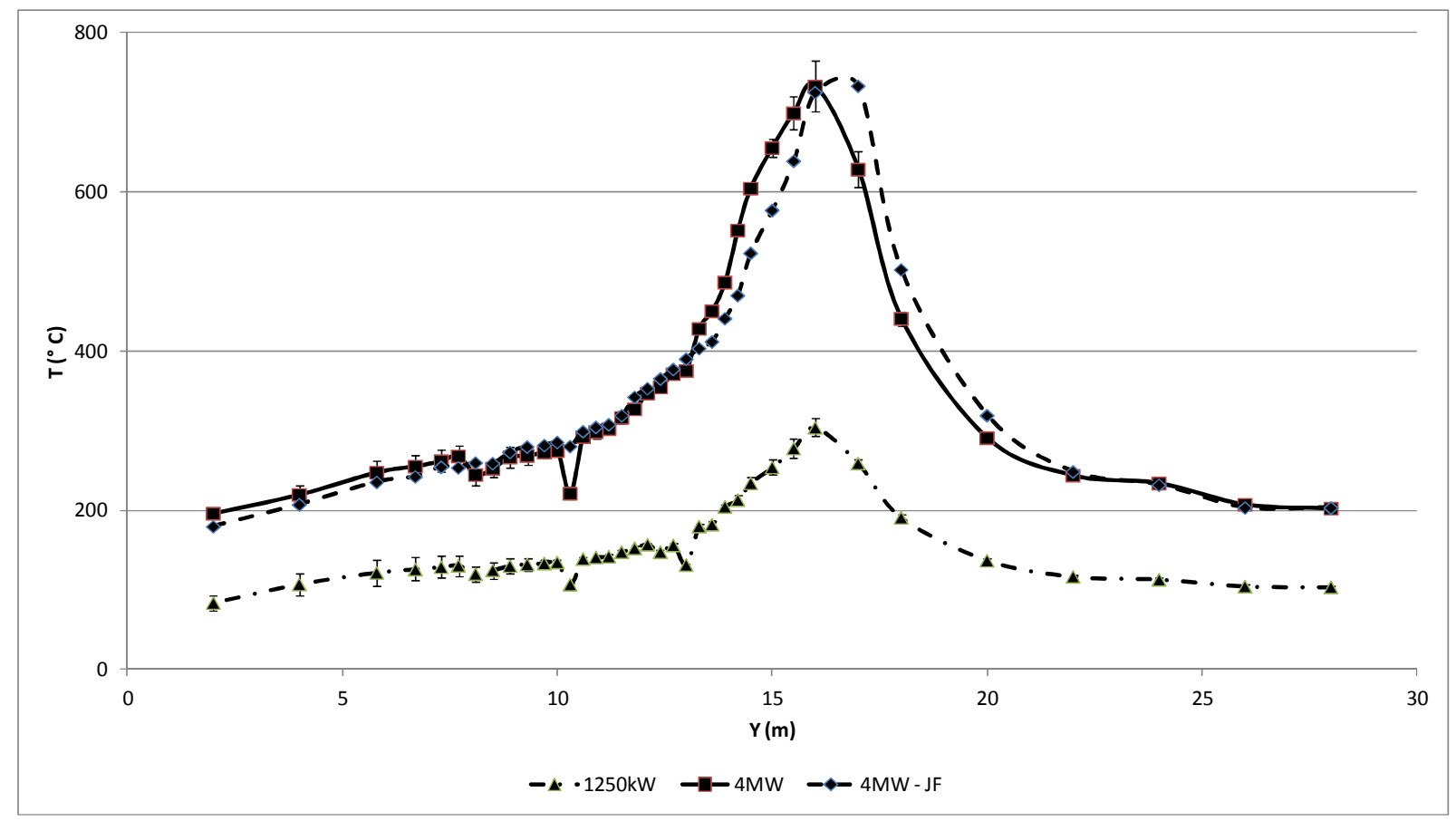

Figure 2. Mean temperature values along the centerline. Configuration: OOOOO. Smoke extraction rate: $200000 \mathrm{~m}^{3} / \mathrm{h}$. JF: jet fans activated.

From temperature profiles as presented in Figure 2, the smoke back-layering distance can be determined [12]. An interface temperature $T_{\text {int }}$ is calculated by means of an $N$-percent rule (with $N=10$ here $): T_{\text {int }}=T_{0}+\left(T_{\max }-T_{0}\right) N / 100$, where $T_{\max }$ is the maximum temperature found on the centerline and $T_{0}$ is the inlet temperature of cold air (taken here as $15^{\circ} \mathrm{C}$ ). The back-layering distance $d$ is determined by the position where the temperature equals $T_{i n t}$. When smoke moves up to the car park inlet and leaves the car park through the inlet, $d$ has been determined by linear extrapolation of the measured temperature profile to negative values of $\mathrm{Y}$. Table 2 provides some results for variable HRR. For obvious reasons, $d$ increases with HRR, given a fixed configuration (OOOOO) and extraction rate. The experiments show very clearly that for the HRR of $4 \mathrm{MW}$, which is in the order of magnitude of a single burning car [4], the ventilation flow rate of 200000 
$\mathrm{m}^{3} / \mathrm{h}$ is not sufficient to keep the smoke back-layering distance below $15 \mathrm{~m}$ (or $10 \mathrm{~m}$ ), the target distance in SHC standards [5-7] for large closed car parks, as mentioned in the introduction. For the set-up at hand, $200000 \mathrm{~m}^{3} / \mathrm{h}$ corresponds to an average air velocity of about $0.72 \mathrm{~m} / \mathrm{s}$, and to about 85 air changes per hour. In $[8,12]$ it is illustrated that almost double the extraction rate is required to meet the mentioned smoke back-layering distance criterion for the set-up at hand and a 4 MW fire.

\begin{tabular}{|l|l|l|l|l|}
\hline HRR $(\mathrm{kW})$ & 500 & 750 & 1250 & 4000 \\
\hline$d(\mathrm{~m})$ & 13.3 & 15.0 & 17.5 & 22.0 \\
\hline
\end{tabular}

Table 2. Smoke back-layering distance as function of fire HRR. Configuration: OOOOO. Extraction rate: $200000 \mathrm{~m}^{3} / \mathrm{h}$. Note: back-layering distance $>13.5 \mathrm{~m}$ implies smoke flowing out of the car park through the inlet opening. These values have been obtained from extrapolation of the data.

\section{b. Impact of Smoke Extraction Flow Rate}
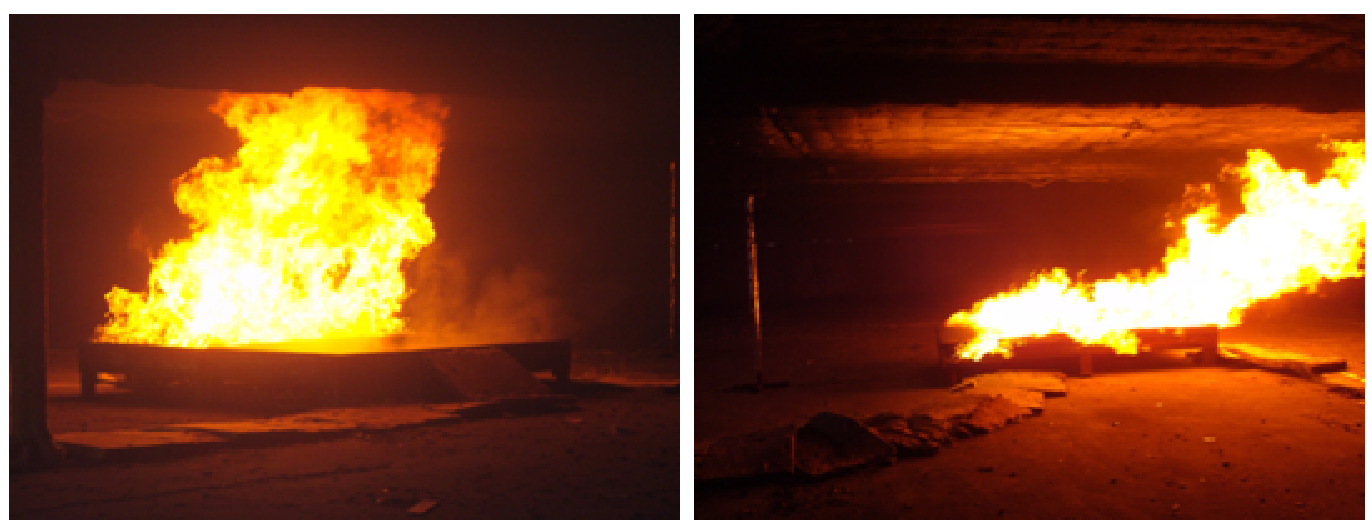

Figure 3. Pictures of a $4 \mathrm{MW}$ fire in the OOOOO (left) and XXOXX (right) configuration. Extraction rate $=200000 \mathrm{~m}^{3} / \mathrm{h}$. 
In this section the impact of the smoke extraction flow rate is discussed, for fixed values of HRR. The discussion is restricted to the $\mathrm{XXOXX}$ configuration, as this configuration provides the largest variation in oncoming air velocity towards the fire source, for a certain variation in smoke extraction flow rate. The inlet opening area is reduced by a factor of 5 , compared to the OOOOO configuration. As such, the average velocities increase by a factor of 5 at the inlet opening (from $0.72 \mathrm{~m} / \mathrm{s}$ to $3.6 \mathrm{~m} / \mathrm{s})$. CFD results indicate that the velocity decreases to about $3.3 \mathrm{~m} / \mathrm{s}$ by the time the air reaches the fire source ([8], Figure 8). This is still much higher than the (approximately constant) value of about $0.72 \mathrm{~m} / \mathrm{s}$ in the OOOOO configuration. Consequently, there is a strong difference in back-ward tilting angle for the flame, as illustrated for a 4 MW fire in Figure 3, due to the much stronger momentum of the oncoming air flow in the XXOXX configuration.

Figure 4 (top) provides mean temperature profiles along the centerline underneath the ceiling in the XXOXX configuration for a range of extraction rates, with the fire HRR fixed at $500 \mathrm{~kW}$. This systematic study has not been repeated for a $4 \mathrm{MW}$ fire, which would be more appropriate in representing a car fire, since Fig. 2 indicates no qualitative difference in the resulting temperature profiles, despite the obvious quantitative differences in temperature (and thus in the driving buoyant force) between a $4 \mathrm{MW}$ fire and a $500 \mathrm{~kW}$ fire. For comparison reasons, the curve for OOOOO and extraction flow rate equal to $200000 \mathrm{~m}^{3} / \mathrm{h}$ is also included.

Obviously, there is a huge difference between the profiles of XXOXX and OOOOO for the extraction rate equal to $200000 \mathrm{~m}^{3} / \mathrm{h}$. As explained, the momentum of the incoming air is much higher in the XXOXX configuration. The Newton force from the SHC system, corresponding to the momentum, overwhelms the Archimedes force (buoyancy) from the fire, the driving force for the smoke dynamics. 
It is instructive to compare the results for XXOXX with extraction flow rate equal to $39000 \mathrm{~m}^{3} / \mathrm{h}$ ) to OOOOO with $200000 \mathrm{~m}^{3} / \mathrm{h}$ extraction rate, as the average velocities at the inlet opening are comparable (approx. $0.7 \mathrm{~m} / \mathrm{s}$ ). Near the fire source, differences between the temperature profiles are small. Behind the fire source (say, $\mathrm{Y}>20 \mathrm{~m}$ ), the temperatures are somewhat higher in the XXOXX configuration. This is logical, since the mass flow rate of incoming cool air, with which the hot gases mix as they move toward the extraction point, is smaller, so that the cooling effect is less pronounced than in the OOOOO configuration with extraction rate equal to $200000 \mathrm{~m}^{3} / \mathrm{h}$. Close to the car park inlet $(\mathrm{Y}=0 \mathrm{~m})$, though, temperatures are also clearly higher for the XXOXX configuration. This confirms that, with respect to smoke back-layering, momentum is important, not velocity by itself: while the average velocities at the car park inlet are comparable, the momentum flow rate in the $\mathrm{XXOXX}$ configuration is about 5 times lower than in the OOOOO configuration (since the mass flow rate is 5 times lower). This explains the higher temperatures or, in other words, the stronger smoke back-layering in the XXOXX configuration.

Comparison of the curves for extraction rate equal to $100000 \mathrm{~m}^{3} / \mathrm{h}$ reveals that the position of the extraction fans hardly affects the temperature profiles. Indeed, the curves labeled 'c' (where the central extraction fans(see Figure 1 for their position) have been activated and the outer fans are shut) and 'o' (where the opposite is true) practically coincide. Recall that the distance between the fire source and the extraction fans is about $13 \mathrm{~m}$. From this observation it can be concluded that the exact position of the extraction fans hardly affects the smoke back-layering (at least if they are not in the immediate neighbourhood of the fire source).

Figure 4 (bottom) also provides the results for the thermocouple lines at $X=9.3 \mathrm{~m}$ and $\mathrm{X}=19.3$ $\mathrm{m}$, i.e. on both sides of the symmetry plane. Except for the extraction rate of $39000 \mathrm{~m}^{3} / \mathrm{h}$, a high level of symmetry is observed: the lines 'l' (left) and ' $r$ ' (right) agree well with each other. The 
temperatures for the extraction rate of $200000 \mathrm{~m}^{3} / \mathrm{h}$ in the XXOXX configuration are low: the fire force is completely overwhelmed, as explained above, and all the heat is effectively removed. Comparison of the results for OOOOO, $200000 \mathrm{~m}^{3} / \mathrm{h}$, to XXOXX, $39000 \mathrm{~m}^{3} / \mathrm{h}$, clearly reveals how the hot smoke is trapped inside the recirculation region behind the $\mathrm{XX}$ zones at the car park inlet opening: while the curves along the centreline (top figure) only deviate for $\mathrm{Y}<6$ $\mathrm{m}$, the temperatures in the XXOXX configuration are higher everywhere towards the sides of the car park (bottom figure). Behind the burner ( $\mathrm{Y}>20 \mathrm{~m}$ ), the higher temperatures for the XXOXX configuration $\left(39000 \mathrm{~m}^{3} / \mathrm{h}\right)$ than for the OOOOO configuration $\left(200000 \mathrm{~m}^{3} / \mathrm{h}\right)$, observed at the centreline, are confirmed closer to the sides of the car park (bottom figure). As explained, this is due to a smaller mass flow rate of fresh air with which the hot gases mix as they flow towards the extraction points.

Table 3 provides the back-layering distance $d$ as function of the smoke extraction rate for the XXOXX configuration and fire HRR $=500 \mathrm{~kW}$. The back-layering distance $d$ is almost the same for the two tests with extraction rate equal to $100000 \mathrm{~m}^{3} / \mathrm{h}$. This confirms that the exact location of the extraction fans, as long as they are not very close to the fire source, does not affect the smoke back-layering. 

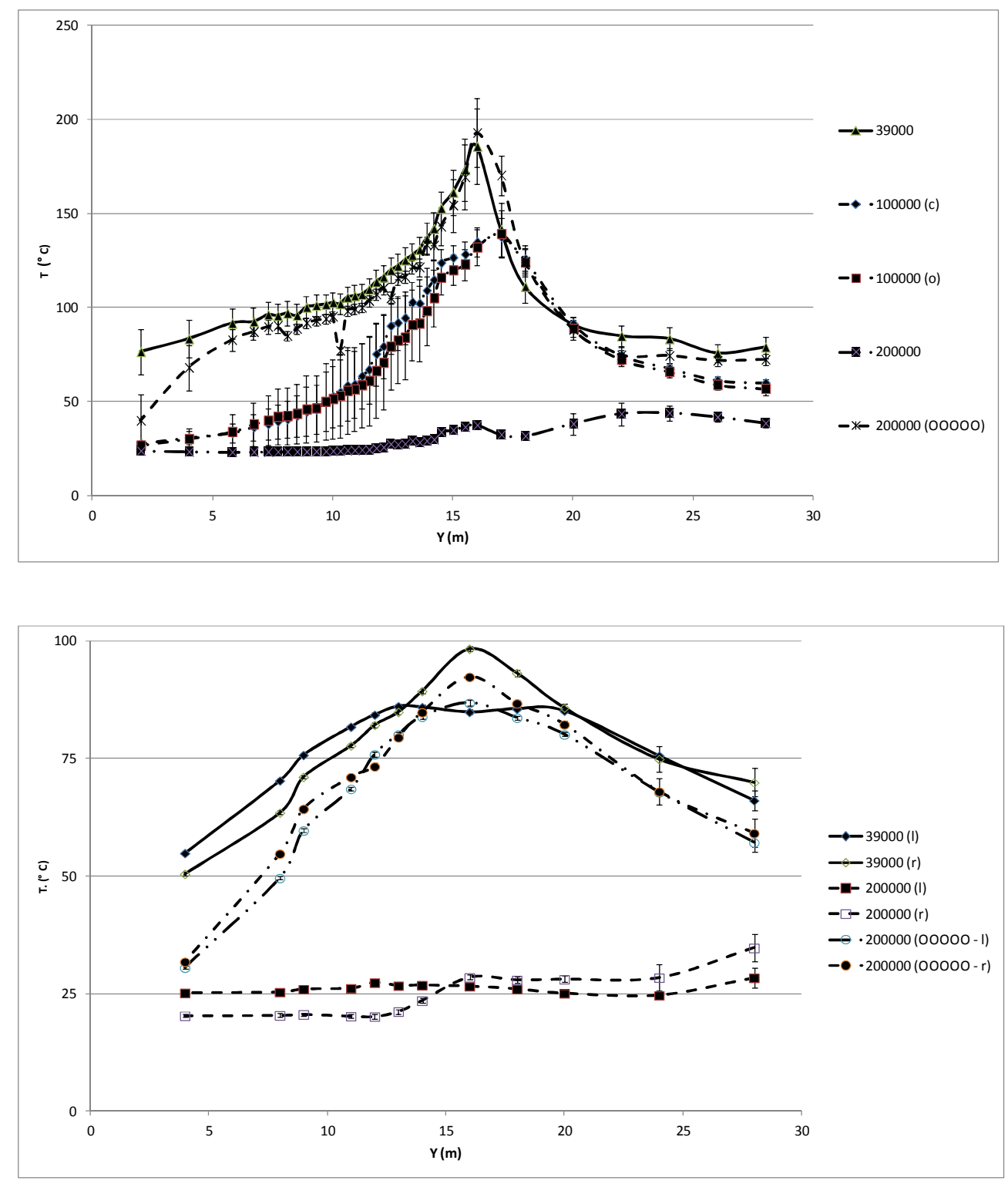

Figure 4. Configuration: XXOXX (unless mentioned otherwise). Fire HRR $=500 \mathrm{~kW}$. Line legend: extraction rate (in $\mathrm{m}^{3} / \mathrm{h}$ ). Top: mean temperature values along the centerline; c: central extraction fans active; o: outer extraction fans active, see Figure 1. Bottom: profiles at $X=9.3 \mathrm{~m}$ ('l') and $\mathrm{X}=19.3 \mathrm{~m}($ ('r').

\begin{tabular}{|l|l|l|l|l|}
\hline Extraction rate $\left(\mathrm{m}^{3} / \mathrm{h}\right)$ & $100000(\mathrm{o})$ & $100000(\mathrm{c})$ & 200000 & $200000-$ OOOOO \\
\hline
\end{tabular}




\begin{tabular}{|l|l|l|l|l|}
\hline$d(\mathrm{~m})$ & 11.1 & 11.5 & 3.6 & 13.3 \\
\hline
\end{tabular}

Table 3. Smoke back-layering distance $d$ as function of smoke extraction rate for XXOXX configuration (unless mentioned otherwise) and fire HRR $=500 \mathrm{~kW}$. The notation 'o' indicates that the outer extraction fans are active and the central ones are shut (see Figure 1). The notation 'c' refers to the opposite situation.

\section{c. Impact of Flow Pattern}

The flow pattern in the previous sections is relatively simple. In the OOOOO configuration, the oncoming ventilation air flow is essentially unidirectional and the smoke is extracted in the same direction. In such circumstances, a car park can be thought of as a very wide tunnel, from a flow pattern point of view. [With respect to combustion, the situation is still different in the sense that a car park fire is typically fuel-controlled, while a tunnel fire can be under-ventilated, precisely as a consequence of the limited horizontal dimensions [13].] In the XXOXX configuration, recirculation regions appear behind the $\mathrm{XX}$ parts [8], but as far as smoke back-layering in the central $\mathrm{O}$ part is concerned, the air and smoke flow remains essentially unidirectional. In the present section, the impact of smoke entering a large recirculation region is considered. To that purpose, the inlet opening has been modified to OXXXO and XXXXO (Table 2). The reader is referred to [8] for an extensive discussion on the flow patterns, based on CFD simulation results. No CFD results are presented here.

The OXXXO configuration is discussed first. Figure 5 shows mean temperature centerline profiles for fire HRR equal to $500 \mathrm{~kW}$ (top) or $4 \mathrm{MW}$ (bottom) and extraction flow rate equal to $200000 \mathrm{~m}^{3} / \mathrm{h}$, with and without jet fans. The profiles for the OOOOO configurations are included for comparison reasons.

The maximum temperature values in the OOOOO and OXXXO configurations are very similar. This is to be expected, since the fire HRR and smoke extraction rate are identical to within 
experimental uncertainty. Near the inlet $(\mathrm{Y}<5 \mathrm{~m})$, temperatures are clearly higher in the OXXXO configuration for the $500 \mathrm{~kW}$ fire: the heat is trapped more in the recirculation region behind XXX, compared to the OOOOO configuration, where there is direct contact with incoming fresh air near the inlet.

A major difference for both HRRs is the position of the peak temperature. Due to back-ward tilting, it is around $\mathrm{Y}=16 \mathrm{~m}$ in the OOOOO configuration, while it is around $\mathrm{Y}=14.5 \mathrm{~m}$ in the OXXXO configuration. This is a direct consequence of the recirculation region behind the XXX blockage at the car park inlet opening [8]. Indeed, the recirculation region extends to the position of the fire source. As a consequence, there is no back-ward tilting of the flames in the OXXXO configuration and the recirculation region is filled with smoke. This is also visible in Figure 6, showing the mean temperature profiles at $\mathrm{X}=9.3 \mathrm{~m}$ and $\mathrm{X}=19.3 \mathrm{~m}$. Compared to the curves for OOOOO, the temperature profiles for $500 \mathrm{~kW}$ are flat in the OXXXO set-up until $\mathrm{Y}=16 \mathrm{~m}$, after which they decrease. This flat region confirms that the recirculation zone is filled with smoke. In the OOOOO configuration, there is a clear 'rise and fall' shape, with the highest values around the burner position. Close to the inlet (low values of $\mathrm{Y}$ ) the smoke is cooled down by the incoming fresh air. This phenomenon is completely absent in the OXXXO configuration. For the HRR of $4 \mathrm{MW}$, the differences are much smaller: the fire is so strong that there is strong backlayering in the OOOOO configuration (see above), so that there are no significant differences from the situation where smoke (and heat) is trapped in the recirculation region behind XXX in the OXXXO set-up.

Behind the burner (say Y > $20 \mathrm{~m}$ ), the temperatures are lower in the OXXXO configuration. This is logical: since there is a global recirculation zone behind the XXX, much of the fresh air bypasses this zone and flows directly towards the extraction fans. Consequently, this air is cooler 
than in the OOOOO configuration. Since the hot gases mix with cooler air as they flow towards the extraction points, their temperature decreases more rapidly.

As before, activation of the jet fans (lines labeled 'JF' in Figures 5) hardly affects the centerline temperature profiles. The global smoke pattern is determined by the smoke extraction rate (and the fire HRR), not so much by the jet fans, for the configuration at hand. The jet fans essentially blow smoke, 'inhaled' from the bottom side of the jet fans, into the smoke below the ceiling. This only leads to a moderate cooling effect, which is even less pronounced than in the OOOOO configuration (where cold fresh air is blown into the smoke layer under the ceiling). For the 4MW case, activation of the jet fans hardly affects the temperature profiles (also not in the OOOOO configuration, for the same reason as just explained: due to the strong smoke backlayering, the jet fans essentially blow hot smoke into the smoke layer below the ceiling under these circumstances).

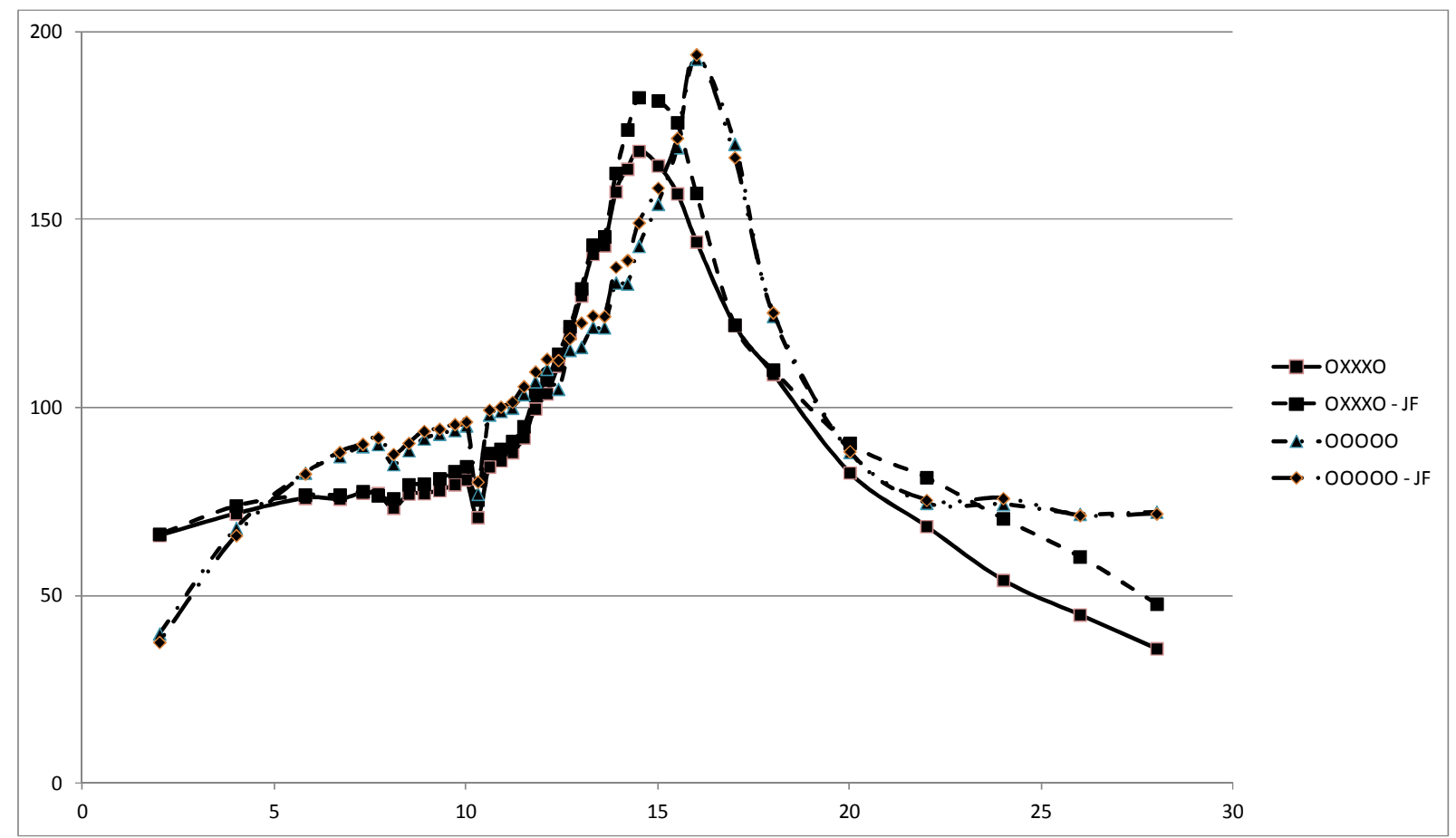




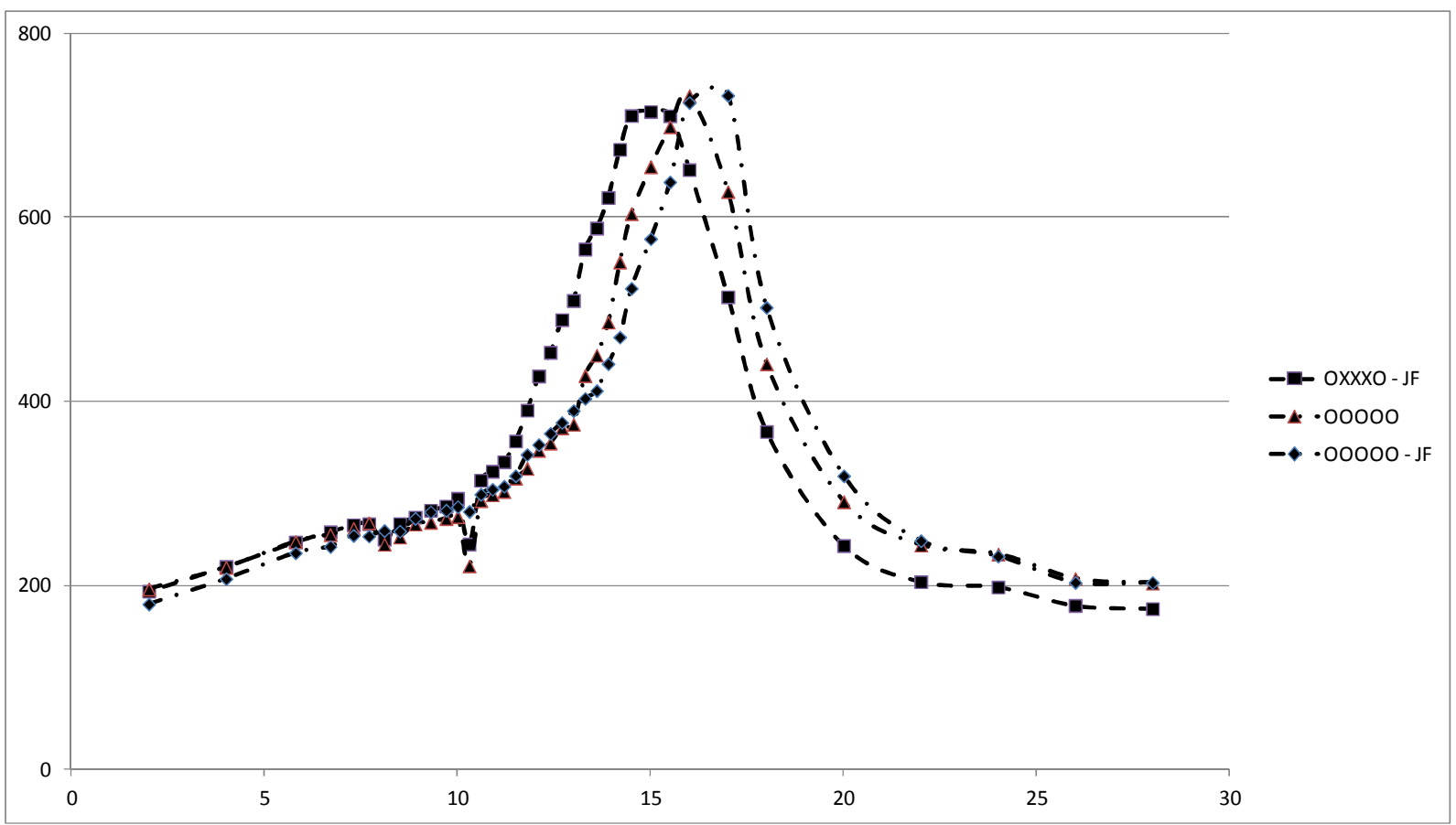

Figure 5. Comparison of configurations OXXXO and OOOOO. JF: jet fans activated. Smoke extraction rate: $200000 \mathrm{~m}^{3} / \mathrm{h}$. Fire HRR $=500 \mathrm{~kW}$ (top) or $4 \mathrm{MW}$ (bottom).

Configuration XXXXO is more complex, as the symmetry is lost. As such, it becomes more complex to compare temperature profiles. In [8], the flow pattern shows features of a clear 'bypass flow' of fresh air from the inlet opening $\mathrm{O}$ towards the extraction fans, as well as a global counter-clockwise recirculation region behind XXXX. For the $500 \mathrm{~kW}$ fire, this pattern is visible at all heights. The $4 \mathrm{MW}$ fire breaks the pattern near the ceiling due to the much stronger buoyant force from the fire. Activation of the jet fans does not substantially modify the flow pattern, nor the temperatures measured [8].

Figure 6 shows mean temperature profiles along the centerline, as well as at $X=4.3 \mathrm{~m}, \mathrm{X}=9.3$ $\mathrm{m}, \mathrm{X}=19.3 \mathrm{~m}$ and $\mathrm{X}=24.3 \mathrm{~m}$, for fire HRR equal to $500 \mathrm{~kW}$ (left) and $4 \mathrm{MW}$ (right) and smoke 
extraction flow rate equal to $200000 \mathrm{~m}^{3} / \mathrm{h}$. The profiles for OOOOO (solid lines) are added for comparison reasons.

The centerline temperature profiles are quite similar for the $4 \mathrm{MW}$ fire (Figure 6, top right), for the reason mentioned: the $4 \mathrm{MW}$ fire is so strong that the temperature profiles along the centerline do not allow to distinguish between the smoke back-layering up to the car park inlet in the OOOOO set-up and the recirculation zone in the XXXXO set-up. Also towards the extraction, differences between the temperature profiles are not large because the fire is so dominant. For the HRR of $500 \mathrm{~kW}$ (top left figure), less backward tilting is observed in the XXXXO configuration. Near the front of the car park $(\mathrm{Y}<5 \mathrm{~m})$ temperatures are higher, due to the recirculation zone. Near the extraction point $(\mathrm{Y}=28 \mathrm{~m})$, the temperature drops in the XXXXO set-up: due to the large recirculation, more fresh air flows by, effectively cooling down the hot gases. Apart from the differences mentioned, the centerline temperature profiles are in fact again quite similar in both set-ups. As was explained for Figure 5, this is not surprising, since the fire HRR and the smoke extraction rate are in principle the same, to within experimental uncertainty.

Larger differences are observed along the other thermocouple lines of Figure 1, though, as could be expected the large differences in flow patterns between OOOOO and XXXXO [8]. The line X $=24.3 \mathrm{~m}$ is situated in the by-pass region in the XXXXO set-up, essentially a virtual corridor of fresh air. Accordingly, hardly any temperature rise is observed in XXXXO for the HRR of 500 $\mathrm{kW}$, whereas there is a clear 'rise and fall' shape in the OOOOO configuration. For the $4 \mathrm{MW}$ case, although the temperatures are globally lower in the XXXXO configuration than in the OOOOO set-up, differences are smaller up to $\mathrm{Y}=16 \mathrm{~m}$ than for the $500 \mathrm{~kW}$ fire. The $4 \mathrm{MW}$ fire is indeed so strong that the hot smoke is pushed into the by-pass region, very much alike its 
pushing effect in the OOOOO set-up. Beyond $\mathrm{Y}=16 \mathrm{~m}$, though, there is a very clear drop in temperature in the XXXXO set-up. The incoming air flow is preferentially extracted by the fan in the right back corner at the 'O' side (Figure 1), and effectively cools down the hot gases as they mix and approach that extraction fan.

The profiles at $X=4.3 \mathrm{~m}$ are supposed to be very similar as the ones at $\mathrm{X}=24.3 \mathrm{~m}$ for the OOOOO configuration. Indeed, they are symmetrically positioned in the car park. Recall, though, that the ceiling has a small slope (see section 2), so that perfectly identical profiles need not be expected. Figure 6 (middle row) confirms the strong similarity of both OOOOO profiles, for both HRR values. In the XXXXO set-up, the symmetry is obviously lost, due to the large recirculation region. As expected, temperatures are higher along $X=4.3 \mathrm{~m}$ (in the recirculation region behind the left ' $\mathrm{X}$ ' in $\mathrm{XXXXO}$ ) than along $\mathrm{X}=24.3 \mathrm{~m}$ (in the corridor of fresh air behind

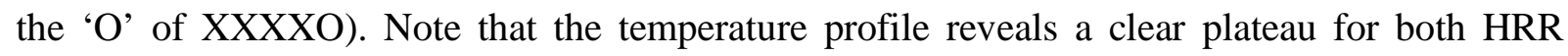
values up to $\mathrm{Y}=25 \mathrm{~m}$ along $\mathrm{X}=4.3 \mathrm{~m}$ in the $\mathrm{XXXXO}$ set-up. This is a clear confirmation of the recirculation flow: there is no flow towards the extraction fan (which would reflect in a 'rise and fall' shape as in the OOOOO results), but rather flow towards the front side of the car park. The strong temperature drop towards $\mathrm{Y}=28 \mathrm{~m}$, also observed along $\mathrm{X}=4.3 \mathrm{~m}$. is due to the fresh air, stemming from the corridor from the $\mathrm{O}$ and flowing towards all extraction fans, essentially by-passing the hot smoke region with the fire behind XXXX.

The profiles along $X=9.3 \mathrm{~m}$ do not differ substantially from the ones along $X=4.3 \mathrm{~m}$, albeit that the presence of the fire source is observed in a more pronounced manner (since the thermocouple line is closer to the fire source): the maximum temperature is higher now. The curves for the OOOOO configuration also differ less than the ones along $X=4.3 \mathrm{~m}$ and $\mathrm{X}=24.3$ $\mathrm{m}$ do, confirming the hypothesis that the differences between those profiles are mainly caused by 
the slope in the ceiling (the height difference between $X=9.3 \mathrm{~m}$ and $\mathrm{X}=19.3 \mathrm{~m}$ is smaller than the difference between $X=4.3 \mathrm{~m}$ and $\mathrm{X}=24.3 \mathrm{~m}$ ).

The profiles along $X=19.3 \mathrm{~m}$ reveal an interesting feature, particularly for the $4 \mathrm{MW}$ fire. Indeed, much higher temperatures are encountered in the XXXXO set-up. This can be of importance when the thermal attack onto the structure is considered. The reason is as follows: the heat from the fire source is 'trapped' inside the recirculation region. It is not cooled by fresh air as effectively as in the OOOOO configuration. Near the extraction point, the temperature drops, as explained below. For the $500 \mathrm{~kW}$ fire, the effect is less pronounced, but the 'rise and fall' shape, not at all visible along $X=9.3 \mathrm{~m}$, is clear along $X=19.3 \mathrm{~m}$.
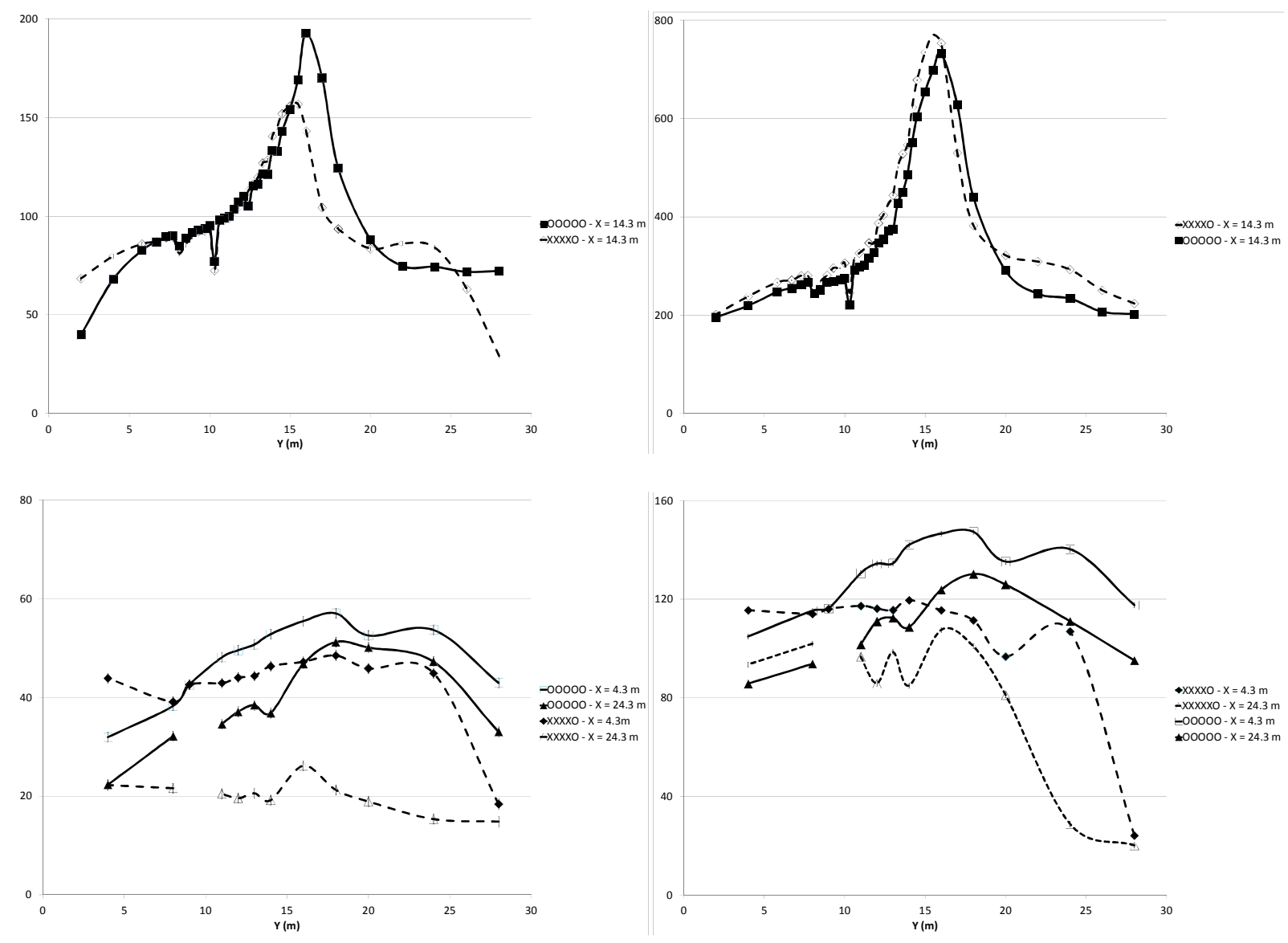


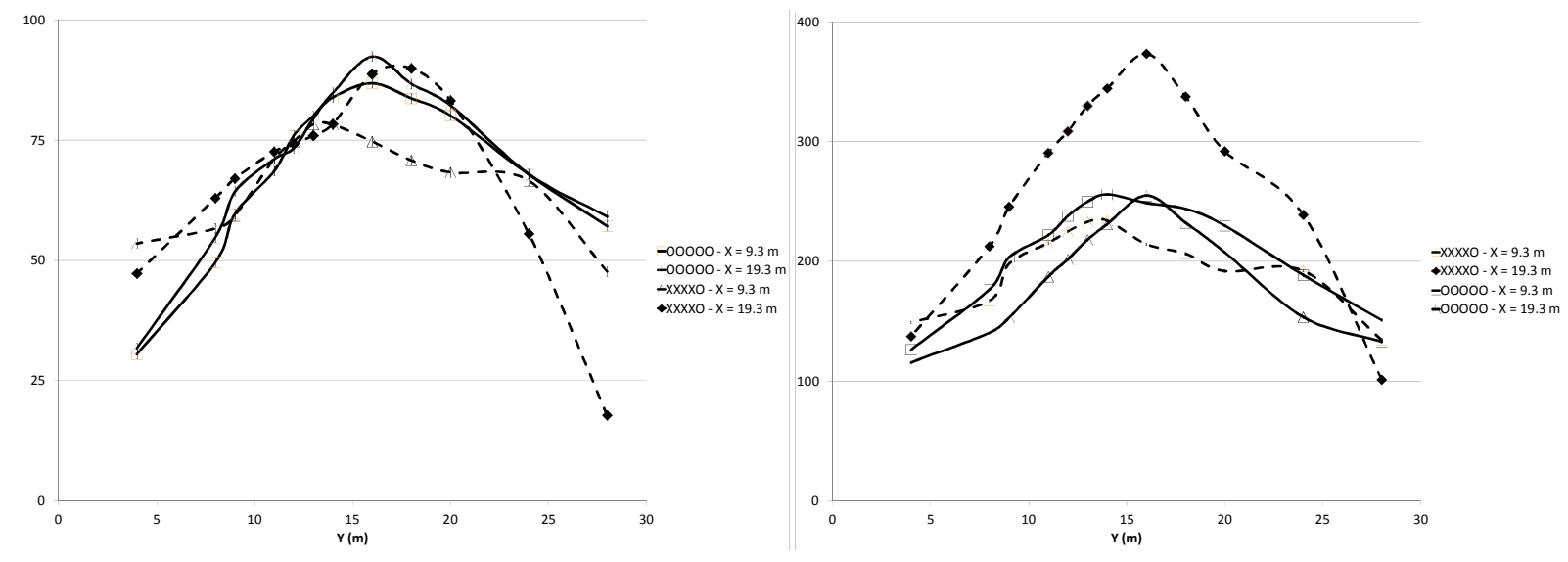

Figure 6. Mean temperature profiles under the ceiling for XXXXO and OOOOO configuration for $\mathrm{HRR}=500 \mathrm{~kW}$ (left) and HRR $=4 \mathrm{MW}$ (right). Extraction rate: $200000 \mathrm{~m}^{3} / \mathrm{h}$.

To conclude this section, Figure 7 illustrates the effect of the fire HRR for XXXXO with extraction rate equal to $200000 \mathrm{~m}^{3} / \mathrm{h}$, without activation of the jet fans. Results are presented for $500 \mathrm{~kW}, 1 \mathrm{MW}, 2 \mathrm{MW}$ and $4 \mathrm{MW}$. The discussion of the profiles for $500 \mathrm{~kW}$ and $4 \mathrm{MW}$ is not repeated here. Obviously, the temperatures increase with increasing fire HRR. Apart from that, all profiles are quite similar in shape, regardless of the absolute value of the fire HRR. This confirms that the impact of the fire HRR on the shape of the smoke pattern back-layering distance is much weaker than the impact of the extraction rate, in line with the analytical formulae of e.g. [12].

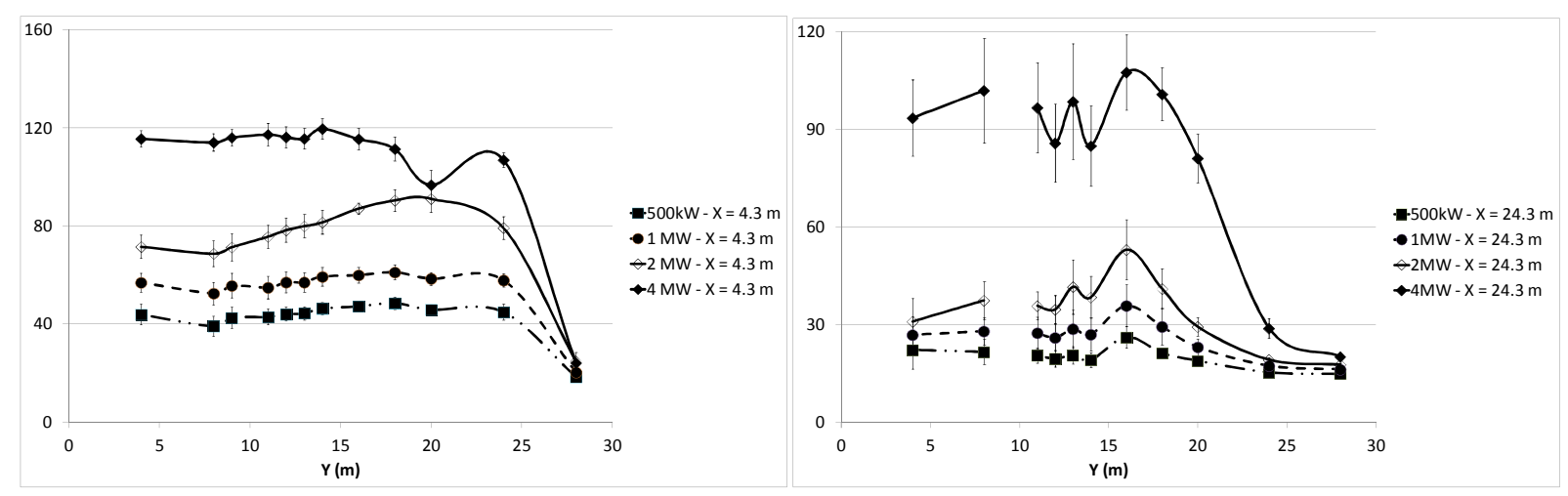



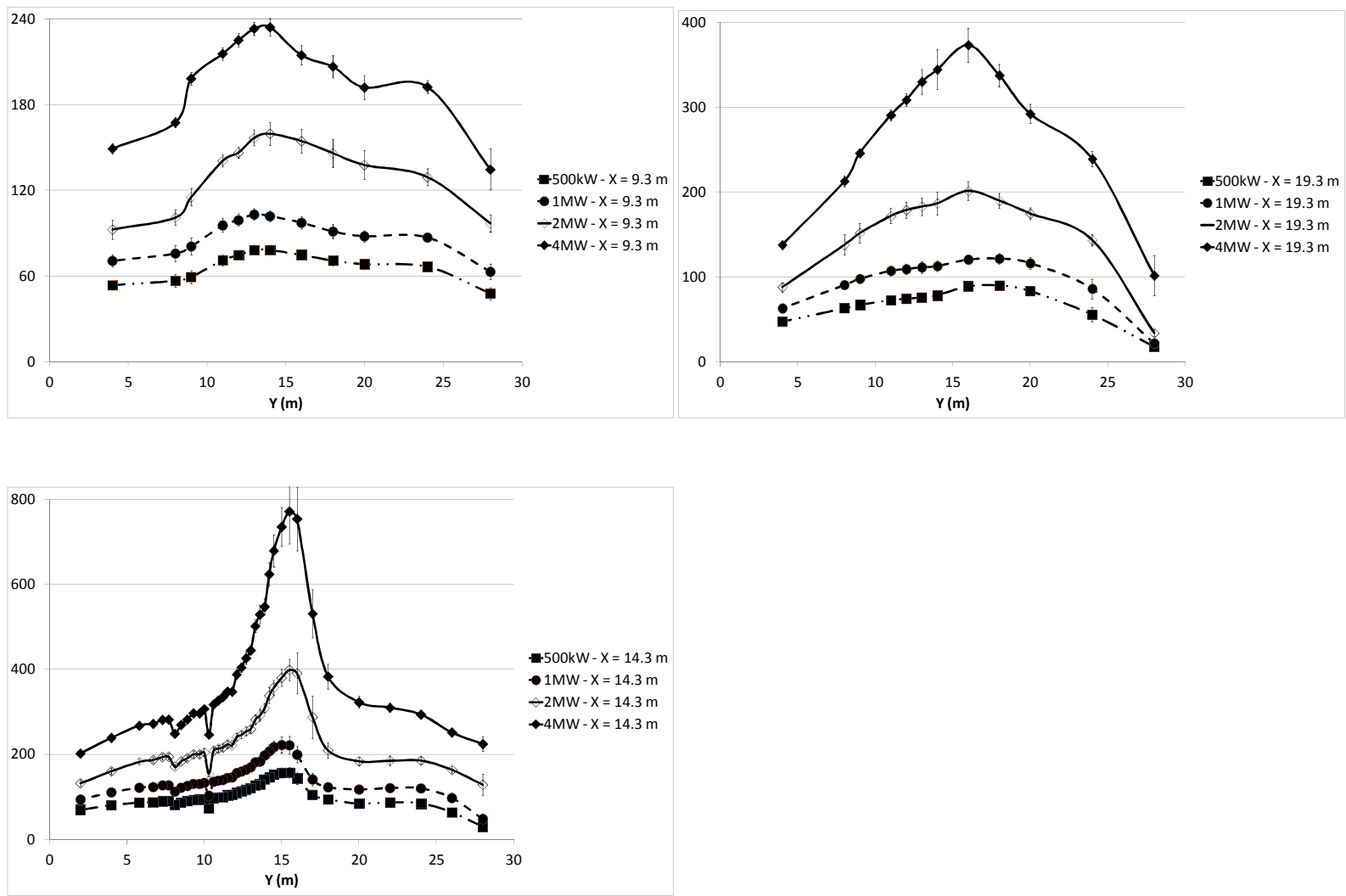

Figure 7. Impact of fire HRR on mean temperature profiles for the XXXXO configuration. Extraction rate: $200000 \mathrm{~m}^{3} / \mathrm{h}$.

\section{d. Impact of Presence of a Transversal Beam}

In section 4.a the possible effect of the longitudinal support beams of $24 \mathrm{~cm}$ depth has already been mentioned. In the present section, the effect of a transversal beam is discussed. The beam is introduced as a $50 \mathrm{~cm}$ deep, $17 \mathrm{~m}$ long plate, positioned centrally in the car park, parallel to the inlet opening, at distance $\mathrm{Y}=10 \mathrm{~m}$ (Figure 1).

Figure 8 presents the mean temperature profiles along the centerline under the ceiling for the OOOOO, XXOXX and OXXXO configurations, with and without the transversal beam, for HRR equal to $500 \mathrm{~kW}$ and $4 \mathrm{MW}$. The jet fans are not activated. 
Comparison of the profiles for $500 \mathrm{~kW}$ in the OOOOO configuration (top figure) reveals the huge impact of the beam. Upstream of the beam $(\mathrm{Y}<10 \mathrm{~m})$, there is practically no temperature rise: the smoke back-layering is effectively blocked. The horizontal momentum of the smoke is broken by the beam and the oncoming air forces the smoke to stay behind the beam $(\mathrm{Y}>10 \mathrm{~m})$. In the region behind the beam, temperatures are clearly higher than when no beam is present: the smoke and heat are trapped behind the beam. Similar observations have been made for the temperature profiles at $X=9.3 \mathrm{~m}$ and $X=19.3 \mathrm{~m}$. Apart from the temperatures being systematically somewhat higher for the configuration with the beam, the profiles at $X=4.3 \mathrm{~m}$ and $X=24.3 \mathrm{~m}$, which are both outside the beam region (Figure 1), are hardly affected. For the HRR of 4 MW the effective blocking of the smoke back-layering by the transversal beam is also very clear. The temperature rise behind the beam, as observed for the $500 \mathrm{~kW}$, is not seen along the centerline, since the temperature was already very high anyway.

For XXOXX (middle figure), the oncoming air flow is so strong that there is no smoke backlayering at all (not even for the $4 \mathrm{MW}$ fire). Interestingly, the main effect of the transversal beam is now the breaking of the horizontal momentum of the oncoming air flow near the ceiling, so that higher temperatures are measured behind the beam. This can result in a more severe thermal attack onto the car park structure.

In the OXXXO configuration (bottom figure), there is a global recirculation zone behind XXX. As a consequence, the transversal beam does not block the smoke back-layering as was the case in the OOOOO set-up: essentially the same temperatures are measured in the region $\mathrm{Y}<9 \mathrm{~m}$. Behind the beam $(\mathrm{Y}>10 \mathrm{~m})$, the increase in temperature is again observed, compared to the situation where no beam is present: the smoke (and heat) cannot flow towards the front side of the car park. 

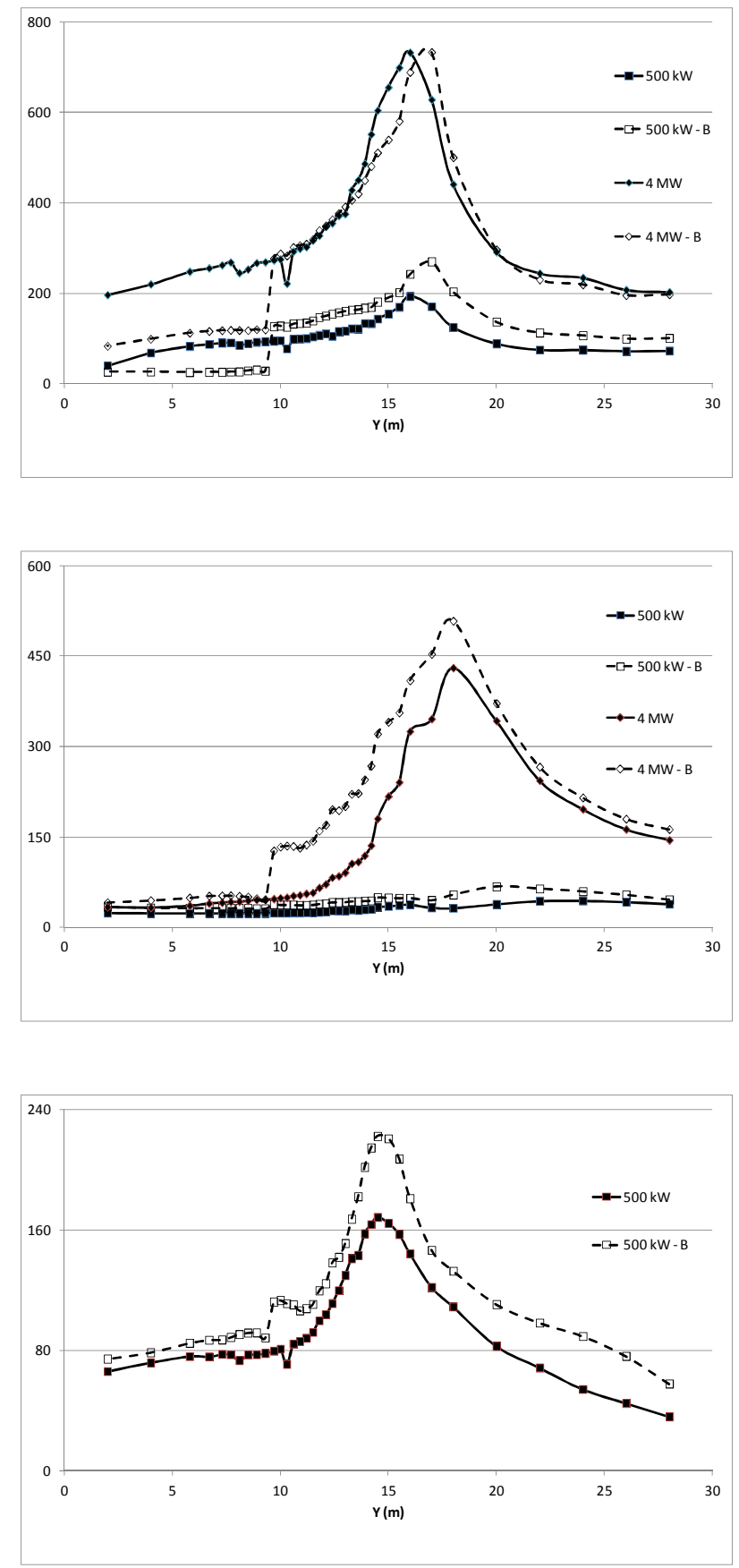

Figure 8. Mean temperature profiles along the centerline under the ceiling. Top: OOOOO; middle: XXOXX; bottom: OXXXO. Extraction rate: $200000 \mathrm{~m}^{3} / \mathrm{h}$. Curves with 'B': transversal beam present.

\section{Concluding remarks}


A selection of temperature measurements from an extensive experimental campaign of full-scale car park fires has been presented. The results have been interpreted in terms of the impact of a smoke and heat control (SHC) system with forced mechanical horizontal ventilation on the smoke pattern in a basic closed car park, given a certain fire (area and heat release rate, HRR).

From a parameter variation, the following aspects can be highlighted:

- the fire HRR directly affects the absolute temperature values, but the resulting impact on the smoke pattern is not very strong. The effect of the extraction rate on the smoke pattern is much stronger than the effect of the fire HRR;

- for a HRR of $4 \mathrm{MW}$, i.e. the order or magnitude for a single burning car, the extraction rate of $200000 \mathrm{~m}^{3} / \mathrm{h}$, corresponding to an average air velocity of about $0.7 \mathrm{~m} / \mathrm{s}$ or about 85 air changes per hour, is not sufficient to prevent smoke back-layering over a distance of less than $15 \mathrm{~m}$ for the car park at hand. This indicates that much higher extraction rates can be required, depending on the configuration studied;

- the inlet velocity of the fresh air is not sufficient by itself to characterize the strength of the ventilation air flow: the momentum, i.e. the product of velocity and mass flow rate, determines the strength. This is a fundamental difference from e.g. tunnel configurations (where, due to the tube-like geometry, the velocity level at the same time determines the momentum, given the (essentially invariant) cross-sectional area);

- by-pass and strong recirculation have been confirmed in the XXXXO (and OXXXO) configuration; as such, smoke (and heat) can be trapped and the thermal attack onto the structure becomes more severe; 
- a transversal beam effectively blocks the smoke, even for high HRR (up to $4 \mathrm{MW}$ ); it is essential to take the presence of beams into consideration during the design process of a SHC system;

- the impact of the exact position of the extraction fans on the smoke pattern is small, when the extraction fans are not close to the fire source;

- the primary effect of jet fans (induction type, $50 \mathrm{~N}$ ) in the study at hand is a local cooling effect, not a significant impact on the global flow pattern. Note that the extraction flow rates have always been much higher than the jet fan flow rates in the study at hand. For the cooling effect to be observed, the jet fans must not be in a smoke filled region.

\section{Acknowledgements}

The results presented have been obtained through the SBO project 080010 , funded by IWT (Flanders, Belgium). The authors say special thanks to all technicians, and to Martin Cambier in particular, for their assistance in setting up the experiments.

\section{References}

[1] M. Shipp et al., 'Fire spread in car parks', BD2552, Department for Communities and Local Government, December 2010.

http://www.communities.gov.uk/documents/planningandbuilding/pdf/1795610.pdf

[2] B. Merci, L. Taerwe, P. Vandevelde, E. Van den Bulck, F. Van den Schoor, J. van Beeck and J. Vantomme, IWT SBO project 080010 (Flanders, Belgium): Fundamental design approaches for improvement of the fire safety in car parks, Deliverable D2.6: Report of full-scale experimental campaign - Smoke and Heat Control (2011).

[3] D. Joyeux, 'Natural Fires in Closed Car Parks: Car Fire Tests', CTICM, INC-96/294dDJ/NB, 1997.

[4] B. Merci and M. Shipp, "Smoke and heat control for fires in large car parks: Lessons learnt from research?", Fire Safety Journal (in press). DOI:

http://dx.doi.org/10.1016/j.firesaf.2012.05.001 
[5] British Standard BS 7346 - 7: "Components for smoke and heat control systems - Part 7: Code of practice on functional recommendations and calculation methods for smoke and heat control systems for covered car parks" (2006).

[6] NBN S21-208-2: "Fire protection inside buildings - Design of smoke and heat exhaust ventilation systems (SHEVS) for indoor car parks", Belgium (2011).

[7] prEN/TS 12101-11: "Smoke and heat control systems - Part 11: Design, installation \& commissioning requirements for enclosed car parks" (2011).

[8] X. Deckers, S. Haga and B. Merci, "Smoke control in case of fire in a large car park: CFD Simulations of Full-Scale Experiments", Fire Safety Journal (in press). DOI:

http://dx.doi.org/10.1016/j.firesaf.2012.02.005

[9] K. McGrattan, S. Hostikka, J. Floyd, H. Baum, R. Rehm, W. Mell, R. McDermott, Fire Dynamics Simulator (Version 5) Technical Reference Guide, NIST 1018-5, National Institute of Standards and Technology (2008).

[10] Y. Wu and M.Z.A. Bakar, "Control of smoke flow in tunnel fires using longitudinal ventilation systems - a study of the critical velocity", Fire Safety Journal 35, pp. 363 - 390 (2000).

[11] B. Merci and P. Vandevelde, "Experimental study of natural roof ventilation in full-scale enclosure fire tests in a small compartment”, Fire Safety Journal 42 (8), pp. 523 - 535 (2007).

[12] N. Tilley, X. Deckers and B. Merci, "CFD Study of Ventilation Velocity and Smoke BackLayering Distance in Car Parks”, Fire Safety Journal 48, pp. 11 - 20 (2012).

[13] A. Beard and R. Carvel, The Handbook of Tunnel Fire Safety, Thomas Telford, London (2005). [ISBN 0-7277-3168-8] 